\title{
Trichinella pseudospiralis vs. T. spiralis thymidylate synthase gene structure and T. pseudospiralis thymidylate synthase retrogene sequence
}

\author{
Elżbieta Jagielska ${ }^{1}$, Andrzej Płucienniczak², Magdalena Dąbrowska' ${ }^{1}$ Anna Dowierciał ${ }^{1}$ and Wojciech Rode ${ }^{\text {** }}$
}

\begin{abstract}
Background: Thymidylate synthase is a housekeeping gene, designated ancient due to its role in DNA synthesis and ubiquitous phyletic distribution. The genomic sequences were characterized coding for thymidylate synthase in two species of the genus Trichinella, an encapsulating T. spiralis and a non-encapsulating T. pseudospiralis.

Methods: Based on the sequence of parasitic nematode Trichinella spiralis thymidylate synthase CDNA, PCR techniques were employed.

Results: Each of the respective gene structures encompassed 6 exons and 5 introns located in conserved sites. Comparison with the corresponding gene structures of other eukaryotic species revealed lack of common introns that would be shared among selected fungi, nematodes, mammals and plants. The two deduced amino acid sequences were $96 \%$ identical. In addition to the thymidylate synthase gene, the intron-less retrocopy, i.e. a processed pseudogene, with sequence identical to the $T$. spiralis gene coding region, was found to be present within the T. pseudospiralis genome. This pseudogene, instead of the gene, was confirmed by RT-PCR to be expressed in the parasite muscle larvae.

Conclusions: Intron load, as well as distribution of exon and intron phases in thymidylate synthase genes from various sources, point against the theory of gene assembly by the primordial exon shuffling and support the theory of evolutionary late intron insertion into spliceosomal genes. Thymidylate synthase pseudogene expressed in T. pseudospiralis muscle larvae is designated a retrogene.
\end{abstract}

Keywords: Trichinella spiralis, Trichinella pseudospiralis, Thymidylate synthase, Gene structure, Introns-late theory, Retrogene

\section{Background}

Trichinella spiralis and Trichinella pseudospiralis are two parasitic nematode species colonizing mammalian striated muscles. Transmission of Trichinella spp. to the next host occurs by ingestion of meat contaminated with the parasite muscle larvae. In the intestine, after mating, adult female worms give birth to the newborn larvae which migrate to the muscles to become the muscle larvae [1]. T. spiralis is an encapsulating species whose muscle larvae reside in discrete structures called nurse cells, separated from myofibers by collagen capsules

\footnotetext{
* Correspondence: w.rode@nencki.gov.pl

${ }^{1}$ Nencki Institute of Experimental Biology, Polish Academy of Sciences, 3

Pasteur Street, 02-093 Warszawa, Poland

Full list of author information is available at the end of the article
}

[2,3]. Instead, muscle larvae of T. pseudospiralis, migrate freely throughout the muscle tissue [1]. Our previous studies documented high thymidylate synthase activity persisting in developmentally arrested muscle larvae of both species, as well as in T. spiralis adult forms $[4,5]$. Thymidylate synthase (EC 2.1.1.45), catalyzing deoxyuridylate methylation to yield a DNA precursor, thymidylate, is the only cellular source of de novo synthesis of the latter [6]. High enzyme activity is known to accompany proliferation, as well as to persist in certain growtharrested systems where it is not associated with cell division cf. [5]. Consequently, while the enzyme expressed in embryos developing in the T. spiralis adult uterus may be considered a marker of proliferation, its localization to excretory-secretory organ, i.e. stichosome, of $T$. spiralis 
adult forms, as well as to gonads and stichosome primordial cells of non-growing muscle larvae, appears to reflect the state of cell cycle arrest [7]. Of note is that high thymidylate synthase activity found in T. spiralis and T. pseudospiralis muscle larvae does not appear to vary in connection with the difference in the intracellular niche occupied by two species.

Thymidylate synthase belongs to the proteins most highly conserved in evolution [6]. It is encoded by a housekeeping gene, considered ancient by virtue of the enzyme's role in DNA synthesis and its ubiquitous phylogenetic distribution [8]. This implies that the gene was likely to play a role in the transition from an RNA to a DNA world and to exist in the common ancestor of modern organisms before kingdoms diverged [9]. Analyses of evolutionary pathways of thymidylate synthase and other ancient genes may serve delineation of the origin of modern DNA sequences and the molecular basis of their evolutionary dynamics [10]. Those genes are also used as models for studying spliceosomal intron distribution among phylogenetic lineages, as the issue of intron loss or gain during evolution of eukaryotic proteincoding genes remains unsettled [11]. Since the discovery of introns, two concepts of their origin have been considered: (i) the introns-early theory or exon theory of genes assumes gene assembly by primordial exon shuffling in a common ancestor of bacteria and eukaryotes, and subsequent massive intron loss over evolution, and (ii) the introns-late theory or insertional theory assumes considerable intron gain during recent times [12]. Of note is that the two theories are also viewed as unlinked rather than incompatible, since introns present in the primordial genes might have been removed and new ones rapidly inserted in different positions [13]. It is also commonly agreed that the last eukaryotic common ancestor had a high intron density $[14,15]$.

T. spiralis thymidylate synthase cDNA has been cloned, allowing determination of the nucleotide and deduced amino acid sequences [16] that turned out to be identical with the gene coding sequence inferred from the recently published draft version of the $T$. spiralis genome [17]. Phylogenetic analysis of amino acid sequences corresponding to the enzymes of different specific origin showed $T$. spiralis thymidylate synthase to branch off before other nematode species and display higher overall similarity with mammalian than other nematode enzymes [16]. Early divergence of the genus Trichinella in the evolution of the phylum Nematoda, as well as differences in the genome characteristics of Trichinella in relation to other nematode lineages were also documented by others $[18,19]$.

The goal of the present study was to characterize the T. pseudospiralis thymidylate synthase cDNA and genomic sequences, in order to perform analysis of introns distribution and compare it with that of the corresponding T. spiralis gene determined previously [20]. Considering previously suggested evolutionary distinctness of the genus Trichinella in the evolution of the phylum Nematoda (see above), of interest was also to compare both Trichinella thymidylate synthase genes with the corresponding genes of various eukaryotic species.

\section{Methods}

\section{Primer sequences}

IVTF: 5' GGGTCTAGACTTGAATGTTATAGATATT TATACAATG 3', IVTR: 5' GGGAAGCTTCCATGAAA TTTTATTTC 3', RGENP: 5' GAGAGCGGCCGCCAA TGACAGAAACTGTTCACAAATTAG 3', RGENK: 5' AAAGCGGCCGCGATCACACAGCCATAGGCATTG 3', RGEN5'1: 5' AAAAGCGGCCGCACGTAATCATCCTGA GATG 3', RGEN5'2: 5' AAAAGCGGCCGCAGCTTTCA GAGAAGAATGTC 3', RGEN3'1: 5' GAGAGCGGCCGC CTATGGCTGTGTGATCAATTG 3', RGEN3'2: 5' GAG AGCGGCCGCCCAAATCACCTTCTTCATAATTG, SYN EX1: 5' GGGGATCCATATGACAGAAACTGTTCACAA ATTAG 3', SYNEX2: 5' AAAAGCTTACACAGCCATAG GCATTGATA 3'.

\section{Biological material}

T. spiralis (ISS 569155 569) and T. pseudospiralis muscle larvae were maintained and isolated, as previously described [5].

\section{Nucleic acids isolation}

Total RNA was isolated from T. pseudospiralis muscle larvae using TRIZOL reagent (Life Technologies) and genomic DNA from muscle larvae of both species was extracted using Wizard Genomic DNA Purification Kit (Promega), with the manufacturer's protocols applied in each case.

\section{Reverse transcription}

This was performed on total RNA prepared from $T$. pseudospiralis muscle larvae with SYNEX2 primer, in two rounds of $1 \mathrm{~h}$ incubation at $42^{\circ} \mathrm{C}$ [16], using MMLV reverse transcriptase (Promega).

\section{Polymerase Chain Reaction (PCR)}

In order to amplify T. pseudospiralis thymidylate synthase ds cDNA, as well as T. spiralis and T. pseudospiralis thymidylate synthase genes, standard PCR on ss cDNA or genomic DNA was performed, using Taq DNA polymerase (Promega), as recommended by the enzyme manufacturer. The following primer combinations and cycling conditions were applied: (i) in the case of T. pseudospiralis thymidylate synthase cDNA, SYNEX1 and SYNEX2 primers were used, with initial $3 \mathrm{~min}$ at $95^{\circ} \mathrm{C}$ and the hot start steps, followed by 35 cycles of $30 \mathrm{sec}$ at $95^{\circ} \mathrm{C}, 30 \mathrm{sec}$ 
at $57^{\circ} \mathrm{C}$ and $1 \mathrm{~min}$ at $72^{\circ} \mathrm{C}$, (ii) in the case of $T$. spiralis gene, RGENP and RGENK primers were used, with initial $2 \mathrm{~min}$ at $95^{\circ} \mathrm{C}$ and the hot start steps, followed by 3 cycles of $15 \mathrm{sec}$ at $95^{\circ} \mathrm{C}, 15 \mathrm{sec}$ at $60^{\circ} \mathrm{C}$ and $2 \mathrm{~min}$ at $72^{\circ} \mathrm{C}$, and subsequent 29 cycles of $15 \mathrm{sec}$ at $95^{\circ} \mathrm{C}, 1 \mathrm{~min}$ at $68^{\circ} \mathrm{C}$ and $2 \mathrm{~min}$ at $72^{\circ} \mathrm{C}$, (iii) in the case of T. pseudospiralis gene, IVTF and IVTR primers were used, with cycling conditions as in (ii), but for the annealing step being performed at $40^{\circ} \mathrm{C}$ in the initial 3 cycles and at $58^{\circ} \mathrm{C}$ in the subsequent 29 cycles. For each amplification a negative control was included. Amplification products were analyzed by electrophoresis in Tris-acetate-EDTA buffered $0.8 \%$ agarose gels.

\section{Inverse PCR}

In order to determine $T$. spiralis thymidylate synthase gene $5^{\prime}$ and $3^{\prime}$ flanking regions, inverse PCR was used [21]. Genomic DNA extracted from $T$. spiralis muscle larvae was digested for $1 \mathrm{~h}$ at $37^{\circ} \mathrm{C}$ with Eco RI (Life Technologies), then ligated overnight at $16^{\circ} \mathrm{C}$ using phage T4 DNA ligase (Promega). A 1/100 dilution of the ligation mixture served as a template for PCR with Taq DNA polymerase (Promega), applied as recommended by the enzyme manufacturer. In the case of the 5 ' region amplification, RGEN5'1/RGEN5'2 primers and the following cycling steps were applied: (i) $2 \mathrm{~min}$ at $95^{\circ} \mathrm{C}$, followed by the hot start step, (ii) 3 cycles of $15 \mathrm{sec}$ at $95^{\circ} \mathrm{C}, 15 \mathrm{sec}$ at $50^{\circ} \mathrm{C}$ and $2 \mathrm{~min}$ at $72^{\circ} \mathrm{C}$, (iii) 29 cycles of $15 \mathrm{sec}$ at $95^{\circ} \mathrm{C}, 1 \mathrm{~min}$ at $68^{\circ} \mathrm{C}$ and $2 \mathrm{~min}$ at $72^{\circ} \mathrm{C}$. In the case of the $3^{\prime}$ region amplification, RGEN3'1/RGEN3'2 primers were used and cycling conditions as described above, but for the annealing step during the initial 3 cycles performed at $60.5^{\circ} \mathrm{C}$. For each amplification a negative control was included. Amplification products were analyzed by electrophoresis in Tris-acetate-EDTA buffered $0.8 \%$ agarose gels.

\section{Cloning and sequencing}

cDNA corresponding to $T$. pseudospiralis thymidylate synthase coding sequence was cloned into $\mathrm{Bam} \mathrm{HI}$ and Hind III sites of pBluescript SK (+) phagemid (Agilent Technologies) propagated in E. coli DH $5 \alpha \mathrm{F}^{\prime}$ strain. DNA amplicons corresponding to $T$. spiralis thymidylate synthase gene and gene flanking regions were cloned into Not I site of the same vector. DNA corresponding to $T$. pseudospiralis thymidylate synthase gene was cloned into Xba I and Hind III sites also into pBluescript SK (+) vector. Sequencing of cloned T. spiralis genomic DNA fragments was performed using Sequenase Version 2.0 DNA Sequencing kit (Affymetrix) and sequencing of T. pseudospiralis thymidylate synthase cDNA and genomic DNA was done by DNA Sequencing and Oligonucleotide Synthesis core facility at the Institute of Biochemistry and Biophysics (Warsaw, Poland).

\section{GenBank submissions}

T. spiralis and T. pseudospiralis thymidylate synthase gene sequences were deposited in the GenBank and are available under accessions [GenBank:AF406808] and [GenBank:KF186231], respectively.

\section{Protein secondary structure analysis}

Crystal structures of thymidylate synthase protein monomers complexed with enzyme substrate deoxyuridylate, dUMP, were obtained from Protein Data Bank (www. rcsb.org), under the accession codes [PDB:4G9U] for T. spiralis, [PDB:4E5O] for M. musculus and [PDB:3HB8] for $H$. sapiens $\mathrm{R} 163 \mathrm{~K}$ mutated enzyme. Secondary structure element assignment for subunit A of each model, was determined by PDB managing system. Graphical structure representation was obtained using VMD 1.8.7 software, implemented with "vmd_use_pdb_ss" script enabling reading of secondary structure elements from PDB files at http://www.ks.uiuc.edu/Research/vmd/.

\section{Ethical approval}

Ethical approval was granted by the First Warsaw Local Ethics Committee for Animal Experimentation at the Nencki Institute.

\section{Results}

$T$. spiralis and T. pseudospiralis thymidylate synthase genes share the same structure and show 11 substitutions at the deduced amino acid sequence level $T$. spiralis and $T$. pseudospiralis thymidylate synthase genes consist of 6 exons, intervened by 5 introns, marked by GT/AG donor/acceptor splice sites (Figure 1). All exons are of the same length and 54 single nucleotide substitutions in 52 codons are found between two species within the 924 nt-long open reading frame (Additional file 1: Figure S1). Out of those, 37 substitutions are identified as transitions, i.e. changes between two purines or two pyrimidines, and 17 are identified as transversions, i.e. changes of purine into pyrimidine and vice versa. Transitions, being twice as frequent as transversions, reminded of the pattern of nucleotide substitutions inferred for human genome based on its pseudogene sequences analysis [22]. Among 54 nucleotide substitutions 42 are silent and 12 result in changes of deduced protein sequence. T. spiralis and T. pseudospiralis thymidylate synthase amino acid sequences show 96\% identity (Additional file 1: Figure S2). The entire 2794 nt-long $T$. spiralis thymidylate synthase gene sequence [GenBank:AF406808] shows 99\% overall identity (BLAST comparison), with the sequence of the corresponding region of $T$. spiralis genome draft [GenBank:NW_003526941]. In both versions the sequences of exons, introns and gene 3' flanking regions are identical. Several single nucleotide differences, i.e. 10 insertions, 


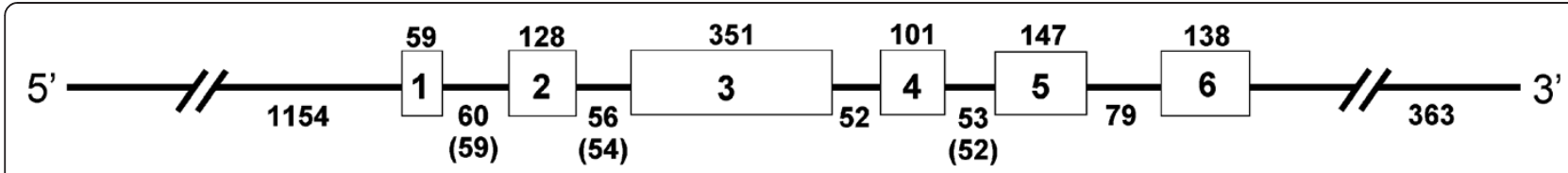

Figure 1 Structures of genes of $T$. spiralis and $T$. pseudospiralis thymidylate synthases. Exons and introns are shown as boxes and lines, respectively. The lengths of $T$. spiralis exons, as well as gene flanking and intronic regions, are given above and below the scheme, respectively. T. pseudospiralis intron lengths when different from T. spiralis, are given in parentheses. The alignment of two sequences is shown as Additional file 1: Figure S1.

1 substitution and 2 deletions, were found only within gene 5' flanking regions. Nine of those differences appear at the sites of single nucleotide stretches, thus resulting presumably from sequence reading obstacles. Within 340 nt of the gene $5^{\prime}$ flanking region consensus TATA box was identified (Additional file 1: Figure S1), implying transcriptional regulation of the parasite gene to be different from mammalian, whose promoters are TATA-less [23].

Two conserved introns and one homologous are present in Trichinella and mammalian thymidylate synthase genes Intron distribution within $T$. spiralis/T. pseudospiralis thymidylate synthase genes was compared with gene structures of other species (Figure 2). The genes of the free-living nematode $C$. elegans and fungus, F. neoformans, the latter being an airways pathogen of immunocompromised patients, contain low intron load, i.e. 2, vs. 4 present in other airways pathogenic fungi species, $P$. carinii, and 5 present in the Trichinella gene. The genes of two other parasitic nematodes, $B$. malayi and L. loa, contain 6 introns, as is also the case for mammalian genes, including human (only B. taurus carries one additional intron). Plant genes appear the richest in introns, with $D$. carota carrying 8 introns within the thymidylate synthase part of its bifunctional dihydrofolate reductase/thymidylate synthase gene. Conserved introns, i.e. present in exactly the same positions, or homologous introns, i.e. those whose positions are shifted (slid) by several nucleotides, are found among animal and fungal genes. Among nematode thymidylate synthase genes four conserved introns are present in Trichinella, B. malayi and $L$. loa genes. Out of those four, two introns corresponding to Trichinella introns 2 and 4, are also found in C. elegans gene, as its only intron burden. Within mammalian thymidylate synthase genes all introns are conserved, with the exception of $B$. taurus intron 7 which remains shifted by $3 \mathrm{nt}$ in relation to the terminus of the corresponding intron 6 present in other mammalian species. The genes of nematodes, with the exception of C. elegans, and those of fungi and mammals contain one conserved intron, corresponding to Trichinella intron 3. This most highly conserved intron is located $11 \mathrm{nt}$ upstream from the junction site of the exon carrying the region coding the enzyme active center. Both plant,
A. thaliana and D. carota genes contain an intron located 12 nt downstream, and $P$. carinii carries an additional intron located $8 \mathrm{nt}$ downstream from that region (intron positions marked on the aligned amino acid sequences are provided as Additional file 1: Figure S3). Thus $P$. carinii enzyme active center is encoded by a separate, $40 \mathrm{nt}$-long exon. The distance between animal/fungal and plant introns situated on the opposite sites of this region, is $44 \mathrm{nt}$. Apart from Trichinella intron 3, animal (with the exception of C. elegans) thymidylate synthase genes contain an additional conserved intron, corresponding to Trichinella intron 5. Additionally, a homologous intron, corresponding to Trichinella intron 2, is present in animal genes, with 3 nt-shift in mammalian vs. nematode genes. Besides, a conserved intron, absent from Trichinella and C. elegans genes, is present in B. malayi, L. loa and mammalian genes as intron 5 . In regard to other intron position homology, F. neoformans and Trichinella genes carry intron 1 shifted by 5 nt between two genes. Introns in plant $A$. thaliana and D. carota thymidylate synthase, parts of the bifunctional genes, are found in the conserved positions with the exception of an additional $D$. carota intron 7 . Yet no common intron is found for plant vs. animal and fungal genes. Intron positions may breake coding sequence between codons (intron phase 0), or after the first or the second base pair (intron phase 1 or 2, respectively) [24]. In fungal and animal thymidylate synthase genes, with the exception of those of B. malayi, L. loa and B. taurus, the intron phases other than 0 are dominating or equally frequent. In B. malayi/L. loa, B. taurus, A. thaliana and $D$. carota genes, phase 0 introns prevail, reaching the numbers 4 out of 6,4 out of 7, 5 out of 7 and 5 out of 8 , respectively. In analogy to the intron phases, also exon phases are defined. The exons beginning and ending with the same phase are called symmetric, in contrast to asymmetric ones, which begin and end with a different phase [24]. In Trichinella and A. thaliana thymidylate synthase genes symmetric exons prevail, reaching the numbers 4 out of 6 and 5 out of 8 , respectively. In $P$. carinii, gene asymmetric exons significantly prevail (4 out of 5). In B. malayi, L. loa and mammalian genes, asymmetric exons are more frequent (4 out of 7 ). This is also the case for C. elegans (2 out of 3), F. neoformans (2 out of 3) and $D$. carota (5 out of 9), genes. In B. taurus the frequency of both types of exons is equal. 


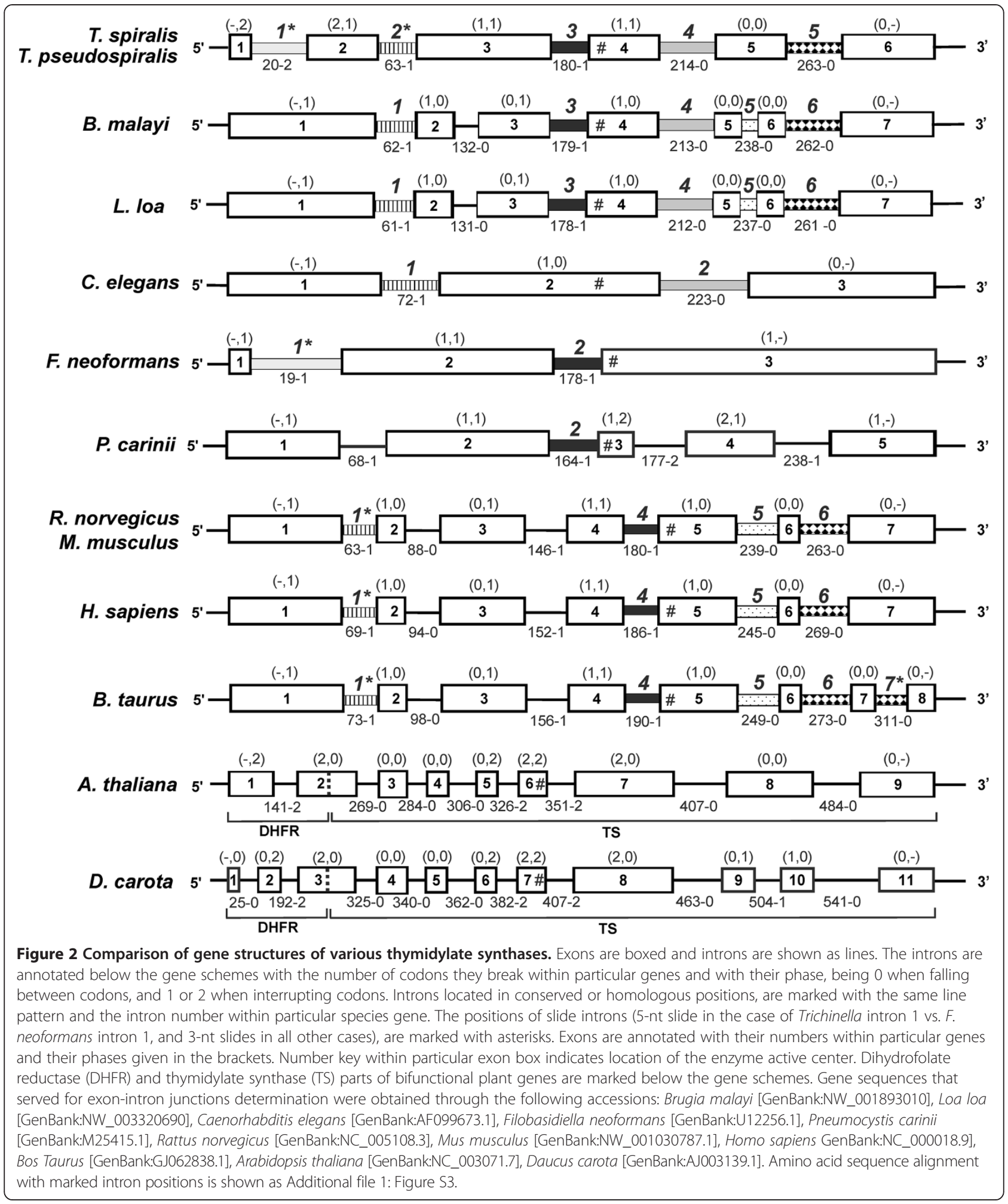


Lack of correlation among location of conserved and homologous introns and the protein secondary structure entities

Location within amino acid sequence of splicing sites of three introns, two conserved and one homologous among $T$. spiralis, $M$. musculus and $H$. sapiens thymidylate synthase genes, and assignment of those sites to the protein spatial structure in enzyme models obtained from PDB, were followed (Figure 3). T. spiralis intron 2 and homologous mammalian intron 1 , both being phase 1 introns (Figure 2), do not separate secondary structure elements. The former lays within a helix and the latter is located within a region assigned in PDB files neither helical nor $\beta$-sheet form. While Trichinella intron 3 is located also within a helix, conserved with it mammalian intron 4 is located at the edge of a helix, despite both introns being of phase 1 . Trichinella intron 5 and conserved mammalian intron 6 , both being phase 0 introns, are located at the edge of helices. No correlation can thus be inferred among intron locations, their phases, and protein secondary structure element borders.

Thymidylate synthase retrogene is expressed instead of the gene in T. pseudospiralis muscle larvae

PCR on T. pseudospiralis genomic DNA resulted in two products, a $1220 \mathrm{nt}$-long amplicon, corresponding to the gene region encompassing exon and intron sequences, and a 924 nt-long amplicon of the sequence identical to $T$. spiralis thymidylate synthase ORF, designated a pseudogene (Figure 4). RT-PCR on RNA isolated from
T. pseudospiralis muscle larvae used as a starting material resulted in a single product (not shown), and sequencing of several bacterial clones revealed its sequence to be identical with that of $T$. spiralis thymidylate synthase cDNA. In view of the latter, a processed pseudogene is apparently expressed in T. pseudospiralis muscle larvae. Ultimately, its genomic sequence is referred to as retrogene. Although none of the clones sequenced carried a sequence that would correspond to T. pseudospiralis thymidylate synthase gene, transcription of the gene cannot be unequivocally excluded.

\section{Discussion}

In the present study T. spiralis and T. pseudospiralis thymidylate synthase genes were found to share exonintron structure. Comparison with the gene structures of other eukaryotes, including animal, fungal and plant species, revealed lack of a common intron. However, a conserved intron is found in the vicinity of the region encoding the enzyme active center in nematode (with the exception of C. elegans), fungal and mammalian genes. In T. pseudospiralis genomic DNA, apart from the gene, thymidylate synthase retrogene was identified, of the sequence identical to T. spiralis thymidylate synthase ORF. This retrogene was found to be expressed, instead of the gene, in the parasite muscle larvae.

Comparison of intron distribution among Trichinella and other eukaryotic thymidylate synthase genes shows lack of a conserved or even slid intron that would be shared by the organisms included in the analysis,
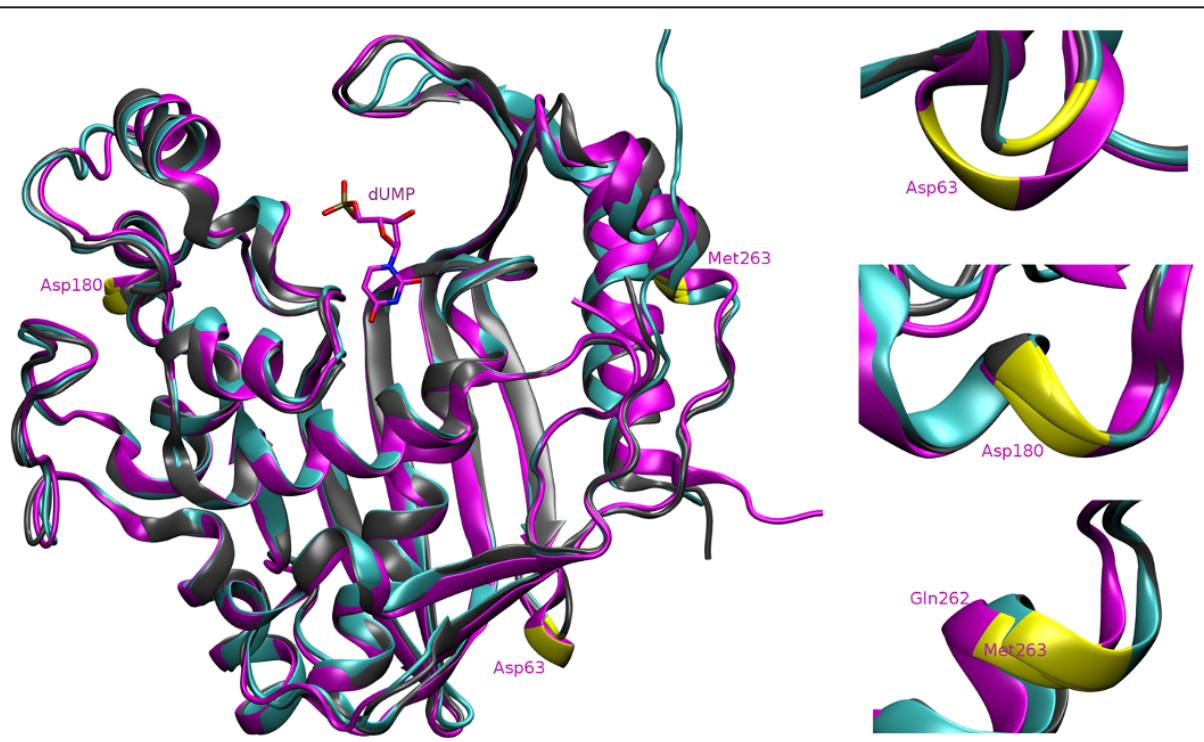

Figure 3 Superimposition of $T$. spiralis (magenta), mouse (cyan) and human (grey) thymidylate synthase structure models of subunits A of dUMP complexes, obtained through the accessions [PDB:4G9U], [PDB:4E5O], [PDB:3HB8], respectively. Secondary structure elements are distinct with helices shown as ribbons, $\beta$-sheets as wide parallel arrows and unclassified regions shown as lines. Derivative sites of homologous intron located at Asp-63 and two conserved introns located at Asp-180 and Gln-262/Met-263 (each amino acid and its number is given for T. spiralis sequence), are marked in yellow with corresponding structural elements shown aside in enlargement. 


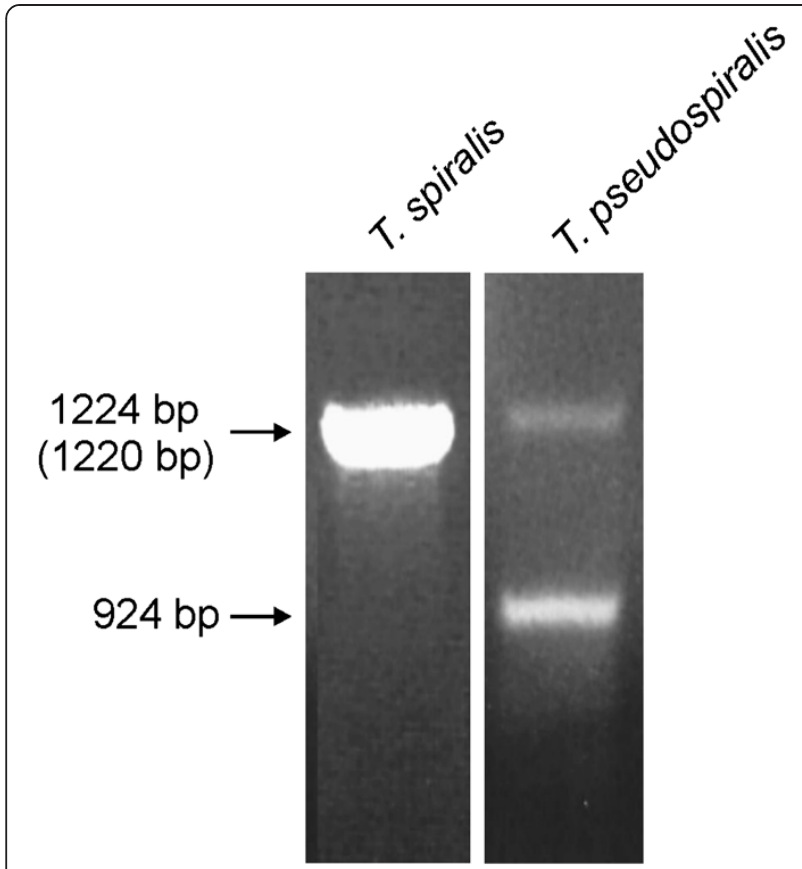

Figure 4 Electrophoretograms of PCR products resulting from amplification of $T$. spiralis and $T$. pseudospiralis genomic DNA, performed with primers specific for the ends of $T$. spiralis thymidylate synthase ORF. The accurate lengths, based on sequencing, are given for T. spiralis and T. pseudospiralis (in parentheses) genes, and for T. pseudospiralis retrogene.

representing animal, plant and fungal crown groups. The intron sliding, termed also intron slippage or drifting, indicates either preexisting intron relocation to a nearby position or its replacement by a new intron at a nearby position. This phenomenon is proposed to be associated with alternative splicing, proceeding by reverse splicing mechanism, i.e. insertion of a spliced-out intron into gene transcript, followed by reverse transcription and homologous recombination. Intron slippage is considered to reflect intron gain events rather than indicate location of an ancient intron, i.e. being remnant from the eukaryotic common ancestor $[11,15,25]$. Among the species studied, the most highly conserved is the intron corresponding to Trichinella intron 3, present also in other nematodes (with the exception of C. elegans), fungal and mammalian genes. As absent from plant genes, it cannot be considered ancient but rather constituting a relic from the common ancestor of fungi and animal evolutionary lineages [26]. Commonality of intron load within animal lineage only is further evident, based on the presence in all nematodes and mammals of an intron homologous to Trichinella intron 2 and conservation of two other introns, one corresponding to Trichinella intron 5 and present in all other species, and the other, absent from Trichinella and C. elegans genes but present in B. malayi, L. loa and mammalian genes as intron 5. An overall lower intron number in $C$. elegans than in other nematode thymidylate synthase genes (2 vs. 5/6), remains in agreement with a notion that $C$. elegans phylogeny, unlike with other nematodes, is characterized by extensive intron loss and restricted intron gain [14,27]. Thus excluding C. elegans, which does not seem to be a representative model for spliceosomal intron studies, it can be inferred that thymidylate synthase genes of all animal species included in the analysis represent a similar intron location pattern. Also plant thymidylate synthase genes show apparently kingdom-specific intron distribution. Therefore, it can be hypothesized that locations of introns in thymidylate synthase genes represent new insertional events, occurring independently in animal and plant kingdoms, with fungi sharing possibly a common thymidylate synthase gene origin with animals. The aforementioned conservation of Trichinella intron 3 in nematodes (with the exception of C. elegans), fungal and mammalian genes may be associated with the downstream proximity of the enzyme active center-coding region. Also in plant $A$. thaliana and D. carota genes, there is an intron located proximally, but downstream from that region highly conserved among various species [6]. The distance (44 nt) between locations of fungal/ animal and plant introns, on the opposite sites of the active center coding-sequence, is too long to result from intron sliding (up to $15 \mathrm{nt}$ are allowed for a slide), and rather too short for coding a functional peptide, considering an assumed minimum evolutionary exon length of 45 base pairs [26]. Therefore, it is not likely that both introns were present in the last common eukaryotic ancestor. Their locations seem to point rather to late insertional events, occurring in the vicinity of 21 base pairs-long region coding the enzyme active center, which remained uninterrupted due to selection pressure. Additionally, only in Trichinella and plant genes the active center-containing exon is symmetric, unlike in other nematode, fungal and mammalian genes, where it is asymmetric. Exon symmetry is claimed to be required for maintenance of the reading frame in the case of exon shuffling [24]. Thus in the majority of thymidylate synthase genes analyzed, the active center-coding exon does not conform to this criterion. According to the exon shuffling theory, not only symmetric exons but also phase 0 introns are believed to be favored [24]. Such intron positions are not predominant in Trichinella, C. elegans, fungal and mammalian genes, except in that of B. Taurus, but in B. malayi, L. leo, B. taurus and plant genes phase 0 introns prevail. However, a high number of phase 0 introns occurs in intron-rich regions and appears correlated with higher overall intron load. Also, in animal and plant thymidylate synthase genes, short exons, associated with phase 0 intron-rich regions, tend to be symmetric. Thus, based on the distribution of intron and exon phases within 
thymidylate synthase genes, and in light of the lack of an ancient intron, the rules apparently governing the evolutionary exon shuffling seem to apply to introns late insertional events. A positive correlation between high intron density and species developmental complexity has been established [13] and an overall high intron complement, evident for mammalian and plant thymidylate synthase genes, conforms to that rule. However, the intron load, similarly high in nematodes, with the exception of $C$. elegans, and mammalian genes, casts doubt on this statement. Interestingly, while the two Trichinella species display thymidylate synthase gene structure similar to other nematodes (with the exception of $C$. elegans), the enzyme sequence similarity analysis implicates early evolutionary divergence of the genus Trichinella from the phylum Nematoda. This observation indicates that sequence and gene structure evolution may not be closely linked phenomena. In summary, analysis of gene structures of various thymidylate synthase genes provides support for the introns-late theory, pointing to a recent acquisition of the introns in the course of eukaryotic spliceosomal gene evolution. This conclusion is also supported by an apparent lack of correlation between conserved or homologous intron locations and the positions of the edge amino acid residues of thymidylate synthase protein secondary structure entities. In respect to the latter, intron insertion seems to proceed rather as a stochastic event. Analogous conclusions were inferred also from the intron load pattern in other ancient housekeeping genes, including actin [28], glyceraldehyde-3-phosphate dehydrogenase [29], triosephosphate isomerase [12,26,30] and tubulin [31].

The present paper reports on thymidylate synthase retrogene identified in $T$. pseudospiralis muscle larvae. Pseudogenes are defective copies of functional genes that accumulated in the genomes of many modern organisms, especially mammals. They tended to be considered as molecular relics, accumulating numerous mutations due to release from selection pressure [32]. Pseudogenes may arise either by duplication of genomic DNA or by retroposition, i.e. reverse transcription primed at poly $\mathrm{A}$ tails of an intron-less transcript, followed by insertion of a transposable element into another genomic location. Pseudogenes arising by the second mechanism, called processed pseudogenes or retropseudogenes, display a low survival rate $[33,34]$. Only $10 \%$ of protein coding genes of the human genome have been estimated to have at least one processed pseudogene. Processed pseudogenes of highly expressed housekeeping genes, including those coding for ribosomal proteins, keratin, glyceraldehyde-3-phosphate dehydrogenase and actin, account for the majority of the total number of $\sim 8000$ human processed pseudogenes [35]. Mouse genome was estimated to contain $\sim 5000$ processed pseudogenes [36]. Thymidylate synthase processed pseudogene incapable of encoding functional enzyme was reported for a mouse fibroblast cell line [37]. Among human and mouse genes, those having multiple copies of processed pseudogenes are predominantly housekeeping genes highly expressed in the germ lines or embryonic cells [36]. Although the vast majority of pseudogenes remain functionally inactive, the evidence is accumulating on the abundance of functional processed pseudogenes, called retrogenes, especially in mammals and insects [33]. In particular, $20 \%$ of human genome processed pseudogenes are believed to be expressed [34].

To our best knowledge, it is not only the first retrogene of a housekeeping gene, but also the first pseudogene in general, described for genus Trichinella. C. elegans genome was estimated to contain $\sim 2000$ pseudogenes [38]. However, this number may not be meaningful for Trichinella whose thymidylate synthase protein sequence [16], as well as gene structure (vide supra), are apparently divergent from those of C. elegans. Understanding the mode of thymidylate synthase retrogene insertion into T. pseudospiralis genome and its transcriptional regulation require further investigation. However, as the muscle larvae of this species move freely within the muscle tissue, in contrast to $T$. spiralis muscle larvae being confined to a capsule, a possibility appears that the retrogene expression accounts for the life style adaptation (cf. [39]). In the absence of the capsule, overall transcription regulation may require hypertranscription of thymidylate synthase gene, in order to maintain high enzyme activity, and consequently high levels of its product. This type of regulation is known to take place for retrogenes of broadly expressed housekeeping genes, located to the autosomal chromosomes during and after male meiosis [33]. This reasoning corresponds with a notion that the energy demands of transcription and splicing may favor selection for compactness in the case of highly expressed and/or rapidly regulated genes $[40,41]$, and thymidylate synthase was identified as highly expressed in Trichinella muscle larvae.

The mechanisms of both phenomena discussed in this paper in regard to Trichinella thymidylate synthase genomic sequences, i.e. relatively high intron load and retroposition, are underlain by reverse transcriptase activity. Thus, high levels of reverse transcription seems to shape genome evolution of this lineage. Analysis of other processed pseudogenes and their flanking sequences is required, in order to identify a putative general mode of retroposition specific for this genus. In mammals, involvement of the L1 LINE retrotransposon has been established [42,43].

\section{Conclusions}

Intron load and distribution within thymidylate synthase genes of various species display kingdom-specific patterns with no conserved or homologous introns shared 
among fungi, animals and plant genes. Locations of conserved and homologous introns within animal genes do not show correlation with the enzyme protein structural motifs borders. This allows us to conclude that intron insertion into thymidylate synthase genes depicts evolutionary late gain events, being rather stochastic in regard to the enzyme structure. Identification of thymidylate synthase retrogene in T. pseudospiralis muscle larvae points to a possibility that compactness of genomic sequence coding for this enzyme may reflect larval adaptation to existence within the muscle tissue in a nonencapsulated form.

\section{Additional file}

Additional file 1: Figure S1. Alignment of T. spiralis and T. pseudospiralis thymidylate synthases exon (bold) and intron (italic) sequences. Additionally, a $98 \mathrm{nt}$-long fragment of the $T$. spiralis gene $5^{\prime}$ flanking region is shown, with putative TATA box underlined, and $29 \mathrm{nt}$-long fragment,

corresponding to $3^{\prime}$ UTR [16], is shown as the gene $3^{\prime}$ flanking region. The whole $T$. spiralis and T. pseudospiralis gene sequences are available through the accessions [GenBank:AF406808] and [GenBank:KF186231], respectively. Nucleotide positions differing between the genes of two species are indicated by asterisks. Alignment was performed using Clustal X software and Genomatix MatInspector software served for consensus TATA box identification. Figure S2. Alignment of T. spiralis and T. pseudospiralis thymidylate synthase amino acid sequences. Amino acid substitutions are marked with asterisks. Enzyme conserved folate and doexyuridylate (active center) binding sites are marked bold. Figure S3. Alignment of amino acid sequences of various thymidylate synthases performed in Clustal $X$ software. The intron positions are marked as boxes for phase 0 introns, elipses for phase 1 introns or pentagons for phase 2 introns. The sequences were obtained via the following accessions: Trichinella spiralis [GenBank: AF406808.3], Trichinella pseudospiralis [GenBank:KF186231], Brugia malayi [GenBank:NW_001893010], Loa loa [Genbank:NW_003320690],

Caenorhabditis elegans [GenBank:AF099673.1], Filobasidiella neoformans [GenBank:U12256.1], Pneumocystis carinii [Genbank:M25415.1], Rattus norvegicus [GenBank:NC_005108.3], Mus musculus [GenBank: NW_001030787.1], Homo sapiens [GenBank:NC_000018.9], Bos taurus [GenBank:GJ062838.1], Arabidopsis thaliana GenBank:NC_003071.7], Daucus carota [GenBank:AJ003139.1].

\section{Competing interests}

The authors declare that they have no competing interests.

\section{Authors' contribution}

EJ performed PCR, molecular cloning and sequencing. AP designed the experiments of fragment amplification and cloning. MD designed data presentation and interpretation. AD performed protein structure studies. WR designed the project and coordinated its implementation. All authors read and approved the final version of the manuscript.

\section{Author details}

${ }^{1}$ Nencki Institute of Experimental Biology, Polish Academy of Sciences, 3 Pasteur Street, 02-093 Warszawa, Poland. ${ }^{2}$ Institute of Biotechnology and Antibiotics, 5 Starościńska Street, 02-516 Warszawa, Poland.

Received: 16 January 2014 Accepted: 27 March 2014

Published: 9 April 2014

\section{References}

1. Pozio E, Zarlenga DS: Recent advances on the taxonomy, systematics and epidemiology of Trichinella. Int J Patrasitol 2005, 35:1191-1204.

2. Dąbrowska M, Skoneczny M, Zieliński Z, Rode W: Nurse cell of Trichinella spp. as a model of long-term cell cycle arrest. Cell Cycle 2008, 7:2167-2178.
3. Despommier DD: How does Trichinella spiralis make itself at home? Parasitol Today 1998, 4:318-323.

4. Dąbrowska M, Zieliński ZZ, Wranicz M, Michalski R, Pawełczak K, Rode W: Trichinella spiralis thymidylate synthase: developmental pattern, isolation, molecular properties and inhibition by substrate and cofactor analogues. Biochem Biophys Res Commun 1996, 288:440-445.

5. Rode W, Dąbrowska M, Zieliński ZZ, Gołos B, Wranicz M, Felczak K, Kulikowski T: Trichinella spiralis and Trichinella pseudospiralis: developmental patterns of enzymes involved in thymidylate biosynthesis and pyrimidine salvage. Parasitol 2000, 120:593-600.

6. Carreras CW, Santi DV: The catalytic mechanism and structure of thymidylate synthase. Annu Rev Biochem 1995, 64:721-762.

7. Gołos B, Dąbrowska M, Wałajtys-Rode E, Zieliński Z, Wińska P, Cieśla J, Jagielska E, Moczoń T, Rode W: Immunofluorescent localization of thymidylate synthase in the development of Trichinella spiralis and Caenorhabditis elegans. Mol Biochem Parasit 2012, 183:63-69.

8. Stern A, Mayrose I, Penn O, Shaul S, Gophna U, Pupko T: An evolutionary analysis of lateral gene transfer in thymidylate synthase enzymes. Syst Biol 2010, 59:212-225.

9. Forterre P: The origin of DNA genomes and DNA replication proteins. Curr Opin Microbiol 2002, 5:525-532.

10. Forterre $P$ : The two ages of the RNA world, and the transition to the DNA world: a story of viruses and cells. Biochimie 2005, 87:793-803.

11. Roy SW, Irimia M: Mystery of intron gain: new data and new models. Trends Genet 2009, 25:67-73.

12. Hurst LD, McVean GT: Molecular evolution: a difficult phase for introns-early. Curr Biol 1996, 6:533-536.

13. Mattick J: Introns: evolution and function. Curr Opin Genet Dev 1994, 4:823-831.

14. Rogozin IB, Wolf YI, Sorokin AV, Mirkin BG, Koonin EV: Remarkable interkingdom conservation of intron positions and massive, lineage-specific intron loss and gain in eukaryotic evolution. Curr Biol 2003, 13:1512-1517.

15. Tarrio R, Ayala FJ, Rodriguez-Trelles F: Alternative splicing: a missing piece in the puzzle of intron gain. P Natl Acad Sci USA 2008, 105:7223-7228.

16. Dąbrowska M, Jagielska E, Cieśla J, Płucienniczak A, Kwiatowski J, Wranicz M, Boireau P, Rode W: Trichinella spiralis thymidylate synthase: CDNA cloning and sequencing, and developmental pattern of mRNA expression. Parasitol 2004, 128:209-221.

17. Mitreva M, Jasmer DP, Zarlenga DS, Wang Z, Abubucker S, Martin J, Taylor CM, Yin Y, Fulton L, Minx P, Yang SP, Warren WC, Fulton RS, Bhonagiri V, Zhang X, Hallsworth-Pepin K, Clifton SW, McCarter JP, Appleton J, Mardis ER, Wilson RK: The draft genome of the parasitic nematode Trichinella spiralis. Nat Genet 2011, 43:228-235.

18. Holterman $M$, van der Wurff $A$, van den Elsen $S$, van Megen $H$, Bongers $T$, Holovachow O, Bakker J, Helder J: Phylum-wide analysis of SSU rDNA reveals deep phylogenetic relationships among nematodes and accelerated evolution toward crown clades. Mol Biol Evol 2006, 23:1792-1800

19. Lavrov DV, Brown WM: Trichinella spiralis mtDNA: a nematode mitochondrial genome that encodes a putative ATP8 and normally structured tRNAs and has a gene arrangement relatable to those of coelomate metazoans. Genet 2001, 157:621-637.

20. Dąbrowska M, Jagielska E, Płucienniczak A, Kwiatowski J, Rode W: Gene structure and expression of Trichinella spiralis thymidylate synthase. In Chemistry and Biology of Pteridines and Folates. Edited by Milstien S, Kapatos G, Levine RA, Shane B. Boston: Kluwer Academic Publishers; 2002:501-505.

21. Ochman H, Gerber AS, Hartl DL: Genetic applications of an inverse polymerase chain reaction. Genet 1988, 120:621-623.

22. Zhang Z, Gerstein M: Patterns of nucleotide substitution, insertion and deletion in the human genome inferred from pseudogenes. Nucleic Acids Res 2003, 31:5338-5348.

23. Lee $Y$, Johnson LF: Transcriptional control elements of the rat thymidylate synthase promoter: evolutionary conservation of regulatory features. Exp Cell Res 2000, 258:53-64.

24. Long M, Rosenberg C, Gilbert W: Intron phase correlations and the evolution of the intron/exon structure of genes. Proc Natl Acad Sci U S A 1995, 92:12495-12499.

25. Stoltzfus A, Logsdon JM Jr, Palmer JD, Doolittle WF: Intron "sliding" and the diversity of intron positions. Proc Natl Acad Sci U S A 1997, 94:10739-10744. 
26. Logsdon JM Jr, Tyshenko MG, Dixon C, D-Jafari J, Walker VK, Palmer JD: Seven newly discovered intron positions in the triose-phosphate isomerase gene: evidence for the introns-late theory. Proc Natl Acad Sci U S A 1995, 92:8507-8511.

27. Kiontke K, Gavin NP, Raynes Y, Roehrig C, Piano F, Fitch DHA: Caenorhabditis phylogeny predicts convergence of harmaphroditism and extensive intron loss. Proc Natl Acad Sci U S A 2004, 101:9003-9008.

28. Hoef-Emden K, Shrestha RP, Lapidot M, Weinstein Y, Melkonian M, Arad SM: Actin phylogeny and intron distribution in bangiophyte red algae (Rhodoplantae). J Mol Evol 2005, 61:360-371.

29. Logsdon JM Jr, Palmer JD: Origin of introns- early or late? Nature 1995, 369:526.

30. Kwiatowski J, Krawczyk M, Kornacki M, Bailey K, Ayala FJ: Evidence against the exon theory of genes derived from the triose-phosphate isomerase gene. Proc Natl Acad Sci U S A 1995, 92:8503-8506.

31. Dibb NJ, Newman AJ: Evidence that introns arose at proto-splice sites. EMBO J 1989, 8:2015-2021.

32. Mighell AJ, Smith NR, Robinson PA, Markham AF: Vertebrate pseudogenes. FEBS Lett 2000, 468:109-114.

33. Kaessmann $H$, Vinckenbosch $N$, Long M: RNA-based gene duplication: mechanistic and evolutionary insights. Nat Rev Genet 2009, 10:19-31.

34. Pan $D$, Zhang $L$ : Burst of young retrogenes and independent retrogene formation in mammals. PloS One 2009, 4:e5040.

35. Zhang Z, Harrison PM, Liu Y, Gertein M: Millions of years of evolution preserved: a comprehensive catalog of the processed pseudogenes in the human genome. Genome Res 2003, 13:2541-2558.

36. Zhang Z, Carriero N, Gerstein M: Comparative analysis of processed pseudogenes in the mouse and human genomes. Trends Genet 2004, 20:62-67.

37. Li $D$, Johnson LF: A mouse thymidylate synthase pseudogene derived from an aberrantly processed RNA molecule. Gene 1989, 82:363-370.

38. Harrison PM, Echols N, Gerstein MB: Digging for dead genes: an analysis of the characteristics of the pseudogene population in the Caenorhabditis elegans genome. Nucleic Acids Res 2001, 29:818-830.

39. Bruschi F, Chiumiento L: Trichinella inflammatory myopathy: host or parasite strategy? Parasit Vectors 2011, 4:42.

40. Jeffares DC, Penkett CJ, Bahler J: Rapidly regulated genes are intron poor. Trends Genet 2008, 24:375-378.

41. Zhu J, He F, Hu S, Yu J: On the nature of human housekeeping genes. Trends Genet 2008, 24:481-484.

42. Gogvadze EV, Buzdin AA: A new mechanism of retrogene formation in mammalian genomes: in vivo recombination during RNA reverse transcription. Mol Biol 2005, 39:364-373.

43. Gogvadze E, Buzdin A: Retroelements and their impact on genome evolution and functioning. Cell Mol Life Sci 2009, 66:3727-3742.

doi:10.1186/1756-3305-7-175

Cite this article as: Jagielska et al.: Trichinella pseudospiralis vs. T. spiralis thymidylate synthase gene structure and T. pseudospiralis thymidylate synthase retrogene sequence. Parasites \& Vectors 2014 7:175.

\section{Submit your next manuscript to BioMed Central and take full advantage of:}

- Convenient online submission

- Thorough peer review

- No space constraints or color figure charges

- Immediate publication on acceptance

- Inclusion in PubMed, CAS, Scopus and Google Scholar

- Research which is freely available for redistribution 